\title{
Identifying and Characterizing Important Trembling Aspen Competitors with Juvenile Lodgepole Pine in Three South-Central British Columbia Ecosystems
}

\author{
Teresa A. Newsome, ${ }^{1}$ Jean L. Heineman, ${ }^{2}$ and Amanda F. Linnell Nemec ${ }^{3}$ \\ ${ }^{1}$ BC Ministry of Forests, Lands and Natural Resource Operations, 200-640 Borland Street, Williams Lake, BC, Canada V2G 4T1 \\ ${ }^{2}$ J. Heineman Forestry Consulting, 2125 E. 5th Avenue, Vancouver, BC, Canada V5N 1 M5 \\ ${ }^{3}$ International Statistics and Research Corp., P.O. Box 39, Brentwood Bay, BC, Canada V8M 1R3
}

Correspondence should be addressed to Teresa A. Newsome, teresa.newsome@gov.bc.ca

Received 12 October 2011; Revised 20 December 2011; Accepted 3 January 2012

Academic Editor: Han Chen

Copyright ( $) 2012$ Teresa A. Newsome et al. This is an open access article distributed under the Creative Commons Attribution License, which permits unrestricted use, distribution, and reproduction in any medium, provided the original work is properly cited.

\begin{abstract}
Critical height ratios for predicting competition between trembling aspen and lodgepole pine were identified in six juvenile stands in three south-central British Columbia ecosystems. We used a series of regression analyses predicting pine stem diameter from the density of neighbouring aspen in successively shorter relative height classes to identify the aspen-pine height ratio that maximized $R^{2}$. Critical height ratios varied widely among sites when stands were 8-12 years old but, by age 14-19, had converged at $1.25-1.5$. Maximum $R^{2}$ values at age 14-19 ranged from $13.4 \%$ to $69.8 \%$, demonstrating that the importance of aspen competition varied widely across a relatively small geographic range. Logistic regression also indicated that the risk of poor pine vigour in the presence of aspen varied between sites. Generally, the degree of competition, risk to pine vigour, and size of individual aspen contributing to the models declined along a gradient of decreasing ecosystem productivity.
\end{abstract}

\section{Introduction}

In south-central regions of British Columbia, Canada, trembling aspen (Populus tremuloides Michx.) forms early-seral mixtures with naturally regenerated or planted lodgepole pine (Pinus contorta Dougl. Ex Loud. var. latifolia Engelm.). Given the low shade tolerance of both these species [1], competitive interactions are an important consideration where the primary objective is lodgepole pine production. Past strategies favoured broadcast removal of trembling aspen for purposes of facilitating lodgepole pine growth and meeting government requirements for unimpeded crop conifer growth [2]. This strategy ignored the important role that trembling aspen plays in forest health (e.g., $[3,4])$ and landscape-level development [5-7]. In recent years, efforts have been made to identify competition indices and ecosystem-specific thresholds that would increase the retention of trembling aspen in juvenile stands [8-10]. Some progress has been made. We now know that within a relatively small geographic range in south-central British Columbia, aspen has greater ability to intercept light and to compete with neighbouring lodgepole pine in productive Sub-Boreal Spruce (SBS) ecological units than in the drier, less productive Interior Douglas-fir (IDF), and the even drier and colder Sub-Boreal Pine Spruce (SBPS) units [9-12]. However, competitive interactions have been highly variable between sites even within the same ecological unit, which Filipescu and Comeau [13] also observed for trembling aspen-white spruce (Picea glauca (Moench) Voss) interactions.

Until now, studies in south-central British Columbia have focused on lodgepole pine responses to neighbouring trembling aspen of equal or greater height $[9,10]$. Less effort has been put into characterizing competitor aspen and their size relationships with lodgepole pine in different ecological units. Further work is required to test the assumption that all aspens taller than target pine are contributing to competition and that this applies equally across ecological units and at a range of stand ages. Knowing whether relative height relationships between trembling aspen and lodgepole pine 
are changing with time would help us evaluate the potential for aspen to have ongoing competitive impacts on lodgepole pine as stands age. Trembling aspen crown characteristics and their ability to intercept light have also been linked to stem size $[12,14]$, so examining the distribution of basal area among individual competing aspen stems could also contribute to our understanding of competition differences between ecological units. Finally, in addition to increasing our understanding of aspen's competitive ability, greater focus on aspen in its own right could provide important management information as climate change proceeds and our valuation of the forest resource shifts.

These information needs prompted us to attempt to identify and characterize principal competitor aspen at different stages of juvenile stand development by reanalysing existing aspen-lodgepole pine data that had been collected from six competition studies in three prominent south-central interior biogeoclimatic zones. These long-term experiments had been established on zonal sites (i.e., mesicsubmesic sites where conditions best reflect macroclimatic conditions of the biogeoclimatic unit) in the SBPS, IDF, and SBS zones where the development of juvenile mixtures of aspen and lodgepole pine had been measured repeatedly over periods of up to 12 years. The original studies examined and reported on aspen-lodgepole pine competitive relationships. Competition thresholds based on aspen density were identified, where competitors were defined as aspen that were as tall or taller than target pine $[9,10]$. The present study makes use of the same data sets, plus additional information collected in 2008 and 2009 at two of the sites, to more precisely characterize the most important competitor aspen. For this study, we use a series of simple regressions to examine the importance of aspen competitors in different height classes relative to target lodgepole pine and to characterize those "principal competitor" (PC) aspen. Specifically, we use statistical analysis to address the following questions for each of the six sites. (1) Can we identify the critical height ratio (CHR) between neighbouring trembling aspen and target lodgepole pine where the importance of competitive effects on pine diameter growth is maximized? (2) What are the characteristics of principal competitor aspen on individual sites at the sampled stand ages? (3) How does the risk to lodgepole pine vigour change with increasing density of principal competitor aspen? We then qualitatively examine trends in CHR and the characteristics of principal competitor aspen to suggest how these factors change with stand age and how they differ within and between individual ecological units.

\section{Methods}

2.1. Study Sites. Data from a total of six sites were included in this analysis (Table 1). Two sites were in the Horsefly variant of the Dry Warm Sub-Boreal Spruce zone (SBSdw1), three sites were in the Fraser variant of the Dry Cool Interior Douglas-Fir zone (IDFdk3), and one site was in the Dry Cold Sub-Boreal Pine-Spruce subzone (SBPSxc) [11]. Longitude, latitude, and elevation for each site were used to obtain climatic information from the web-based tool Climate BC
[15] (Table 1). These zonal sites had submesic to mesic soil moisture regimes, were flat to gently undulating $(0-10 \%$ slope) with variable aspect, and ranged in elevation from 900 to $1150 \mathrm{~m}$. They were clearcut harvested between 1977 and 1989. Five of the six sites were not mechanically prepared and regenerated naturally to pure mixtures of lodgepole pine and trembling aspen. The sixth site was ripped and planted with $1+0$ container grown lodgepole pine. Lodgepole pine and aspen were the dominant vegetation species on all sites. Low stature herbs and shrubs were present in the understory at all sites but were not considered to substantially influence competitive relationships between aspen and pine. Understory species composition varied according to ecological unit and is described more fully in previous publications $[9,10,16]$.

2.2. Sampling Design. Data were collected from a total of 713 lodgepole pine-centred subplots across the six sites. Four of the sites were part of a retrospective study that was established in 1992 to investigate lodgepole pine performance at naturally occurring densities; no treatments were applied. Lodgepole pine were selected within $5 \mathrm{~m}$ on either side of a randomly located transect and assigned to classes according to overtopping aspen cover within a $1.78 \mathrm{~m}$ radius of the selected tree. This process continued until the target of approximately seven subplots in each of seven cover classes was achieved. Initial results from the retrospective study sites focused the study on aspen density rather than cover. Additional subplots were established, in 1994 at the SBS sites and in 1997 at the IDF sites, along the existing transects to create a more even distribution across density classes (Table 1). The other two studies included in the present analysis were variable aspen density experiments, where manual cutting treatments were applied to manipulate aspen density according to a randomized complete block design (Table 1). For these studies, the closest acceptable lodgepole pine to grid points that had been prelocated at $10 \times 10 \mathrm{~m}$ spacing were selected as target trees. The variable density studies include pine growing at naturally occurring densities (untreated control) and pine growing in neighbourhoods where aspen density had been reduced when stands were 11 (SBPSxc) and 6 (IDFdk3) years old (Table 1). Newsome et al. $[9,10,16]$ fully describe methods used for both the retrospective and the variable density studies. In all cases, target lodgepole pine were free of major defects and, on naturally regenerated sites, were old enough to have regenerated within 5 years of the harvest date.

2.3. Measurements. Target lodgepole pine were assessed for ground-level stem diameter $(\mathrm{GLD})( \pm 0.1 \mathrm{~cm})$ and height $( \pm 5 \mathrm{~cm})$ and were assigned, according to Newsome et al. [16], to one of four vigour classes: good, fair, poor, or dead, where moribund trees were considered dead. At each assessment date (Table 1), within $1.78 \mathrm{~m}$ radius subplots around each target pine, neighbouring aspen as tall or taller than the target pine were assessed for GLD $( \pm 0.1 \mathrm{~cm})$, height $( \pm 5 \mathrm{~cm})$, and stem-to-stem distance from the target pine. The $1.78 \mathrm{~m}$ subplot radius had originally been selected to allow comparison of competition indices with other studies (e.g., [18]) and was retained because correlation analysis 
TABLE 1: Site, climate, and treatment information for study sites.

\begin{tabular}{|c|c|c|c|c|c|c|}
\hline Site & SBPSxc & IDFdk3-A & IDFdk3-B & IDFdk3-C & SBSdw1-A & SBSdw1-B \\
\hline \multicolumn{7}{|l|}{ Site characteristics } \\
\hline Location & Clusko R. & Meldrum Cr. & Moffat L. & Meldrum Cr. & Hayfield & Two Mile L. \\
\hline Latitude/longitude & $\begin{array}{l}52^{\circ} 29^{\prime} \mathrm{N} / \\
124^{\circ} 06^{\prime} \mathrm{W}\end{array}$ & $\begin{array}{c}52^{\circ} 0^{\prime} \mathrm{N} / \\
122^{\circ} 20^{\prime} \mathrm{W}\end{array}$ & $\begin{array}{l}52^{\circ} 05^{\prime} \mathrm{N} / \\
121^{\circ} 50^{\prime} \mathrm{W}\end{array}$ & $\begin{array}{l}52^{\circ} 01^{\prime} \mathrm{N} / \\
122^{\circ} 20^{\prime} \mathrm{W}\end{array}$ & $\begin{array}{l}52^{\circ} 06^{\prime} \mathrm{N} / \\
121^{\circ} 21^{\prime} \mathrm{W}\end{array}$ & $\begin{array}{c}52^{\circ} 05^{\prime} \mathrm{N} / \\
121^{\circ} 23^{\prime} \mathrm{W}\end{array}$ \\
\hline Elevation (m) & 1125 & 900 & 1045 & 900 & 1097 & 1025 \\
\hline BEC unit/site series & SBPSxc/01 & IDFdk3/01 & IDFdk3/01 & IDFdk3/01 & SBSdw1/01 & SBSdw1/01 \\
\hline Site index $(m)^{1}$ & 13.8 & 20.5 & 20.5 & 20.5 & 21.8 & 21.8 \\
\hline \multicolumn{7}{|l|}{ Climate $^{2}$} \\
\hline Mean annual precipitation ( $\mathrm{mm})$ & 377 & 445 & 513 & 467 & 612 & 601 \\
\hline Mean annual temperature $\left({ }^{\circ} \mathrm{C}\right)$ & 1.7 & 4.0 & 3.2 & 4.3 & 2.7 & 3.0 \\
\hline Average frost-free period (days) & 26 & 91 & 72 & 95 & 65 & 69 \\
\hline $\mathrm{GDD}\left({ }^{\circ} 5 \mathrm{C}\right)$ & 827 & 1288 & 1096 & 1345 & 1001 & 1047 \\
\hline Date of harvest & 1989 & 1980 & 1981 & 1980 & 1978 & 1977 \\
\hline Site preparation date and method & $\mathrm{n} / \mathrm{a}$ & Ripping 1992 & $\mathrm{n} / \mathrm{a}$ & $\mathrm{n} / \mathrm{a}$ & $\mathrm{n} / \mathrm{a}$ & $\mathrm{n} / \mathrm{a}$ \\
\hline Date of brushing treatment & 2001 & 1998 & $\mathrm{n} / \mathrm{a}$ & $\mathrm{n} / \mathrm{a}$ & $\mathrm{n} / \mathrm{a}$ & $\mathrm{n} / \mathrm{a}$ \\
\hline Regeneration method & Natural & Planted & Natural & Natural & Natural & Natural \\
\hline Type of study & \multicolumn{2}{|c|}{ Variable density } & \multicolumn{4}{|c|}{ Retrospective (no treatment) } \\
\hline \multirow{4}{*}{ Treatments } & $1000 \mathrm{sph}$ & $1000 \mathrm{sph}$ & $\mathrm{n} / \mathrm{a}$ & $\mathrm{n} / \mathrm{a}$ & $\mathrm{n} / \mathrm{a}$ & $\mathrm{n} / \mathrm{a}$ \\
\hline & $2500 \mathrm{sph}$ & $2500 \mathrm{sph}$ & $\mathrm{n} / \mathrm{a}$ & $\mathrm{n} / \mathrm{a}$ & $\mathrm{n} / \mathrm{a}$ & $\mathrm{n} / \mathrm{a}$ \\
\hline & $1 \mathrm{~m}$ radius & $4000 \mathrm{sph}$ & $\mathrm{n} / \mathrm{a}$ & $\mathrm{n} / \mathrm{a}$ & $\mathrm{n} / \mathrm{a}$ & $\mathrm{n} / \mathrm{a}$ \\
\hline & No treatment & No treatment & $\mathrm{n} / \mathrm{a}$ & $\mathrm{n} / \mathrm{a}$ & $\mathrm{n} / \mathrm{a}$ & $\mathrm{n} / \mathrm{a}$ \\
\hline Number of blocks & 5 & 3 & $\mathrm{n} / \mathrm{a}$ & $\mathrm{n} / \mathrm{a}$ & $\mathrm{n} / \mathrm{a}$ & $\mathrm{n} / \mathrm{a}$ \\
\hline Assessment years ${ }^{3}$ & $\begin{array}{l}2001,2003 \\
2005,2008\end{array}$ & $\begin{array}{l}2002,2004 \\
2006,2009\end{array}$ & \multicolumn{2}{|c|}{ 1992, 1995, 1999, 2004} & \multicolumn{2}{|c|}{ 1992, 1994, 1999, 2004} \\
\hline
\end{tabular}

${ }^{1}$ For lodgepole pine [17].

${ }^{2}$ Based on information from Climate BC [15].

at stand ages of 15-19 years indicated that the strength of relationships did not increase when the neighbourhood radius was increased [16]. Aspen basal area per hectare (based on GLD) was calculated.

\subsection{Analysis}

2.4.1. Determination of the Critical Height Ratio (CHR). For selected assessment years at each site, the ratio of aspen to target pine height (HR) was calculated for each aspen that was at least as tall as the target pine and within the associated $1.78 \mathrm{~m}$ subplot. Using these ratios, a series of simple regression models was developed to predict lodgepole pine stem diameter growth (between successive assessment years) from the density of aspen with $\mathrm{HR} \geq h$ (at the beginning of each interval), where $h$ was increased, in increments of 0.25 , from a minimum of 1 up to a maximum of 2.5 or 6 , depending on year and site. Model 1 was adopted for the IDFdk3-B, IDFdk3-C, SBSdw1-A, and SBSdw1-B retrospective studies, and Model 2 was adopted for the SBPSxc and IDFdk3-A variable density studies (where an extra term was required to achieve a satisfactory fit at the low end of the aspen density distribution):

$$
\begin{gathered}
\log _{10}(y)=\beta_{0}+\beta_{1} x_{h}+\varepsilon \quad(\text { Model } 1) \\
\log _{10}(y)=\beta_{0}+\beta_{1} x_{h}+\frac{\beta_{2}}{\left(1+x_{h}\right)}+\varepsilon \quad(\text { Model 2), }
\end{gathered}
$$

where $y$ is lodgepole pine diameter growth for a given measurement period, $\beta_{0}$ is the intercept, $\beta_{1}$ and $\beta_{2}$ are regression coefficients, $x_{h}$ is the density of aspen with HR $\geq$ $h(h=1,1.25,1.5$, etc.), and $\varepsilon$ is the residual error (with a correlation structure that depended on the sampling design). Selection of measurement periods, which determined the initial ages of the target pine and lengths of the intervals, was limited by data collection years and therefore was somewhat different between sites (Table 2). Only subplots with at least one aspen in the height ratio class of interest could be included in the analysis. Therefore, as the HR tested increased, the number of subplots contributing to the analysis decreased (Table 2).

Coefficients of determination $\left(R^{2}\right)$ were determined for each regression model. The critical height ratio (CHR) for each site was defined to be the value of $h$ (in the sequence $h=1,1.25,1.5 \ldots)$ where $R^{2}$ was maximized. Aspen with $\mathrm{HR} \geq \mathrm{CHR}$ are hereafter called "principal competitor aspen." In order to compare density and basal area as predictors of lodgepole pine stem diameter growth, Models 1 and 2 were also used to predict lodgepole pine stem diameter growth from the basal area of principal competitor aspen $\left(\mathrm{cm}^{2} / 10 \mathrm{~m}^{2}\right.$ subplot) at each site and to calculate the corresponding $R^{2}$, for each assessment year for which CHR was determined.

For each site and year where CHR was determined, summary statistics (mean and standard error) were calculated to characterize the population of principal competitor aspen. 
TABLE 2: Critical height ratio (CHR) model coefficients, correlation coefficients $\left(R^{2}\right)$, and the proportion of subplots having at least one principal competitor (PC) aspen.

\begin{tabular}{|c|c|c|c|c|c|c|c|c|c|c|c|c|c|}
\hline Site & Year & $\begin{array}{l}\text { Stand age } \\
\text { CHR } \\
\text { determined } \\
\text { (years) }\end{array}$ & $\begin{array}{l}\text { Subsequent } \\
\text { growth } \\
\text { interval } \\
\text { (years) }^{1}\end{array}$ & $n^{2}$ & CHR & $b_{0}$ & $\operatorname{Pr}>|t|$ & $b_{1}$ & $\operatorname{Pr}>|t|$ & $b_{2}$ & $\operatorname{Pr}>|t|$ & $R^{2}(\%)$ & $\begin{array}{c}\% \text { subplots } \\
\text { with } \geq 1 \mathrm{PC} \\
\text { aspen }(\%)\end{array}$ \\
\hline \multirow{2}{*}{ SBPSxc } & 2001 & 11 & 2 & 304 & 3.25 & -0.343 & $<0.0001$ & -0.013 & 0.022 & 0.242 & $<0.0001$ & 25.3 & 66 \\
\hline & 2005 & 15 & 3 & 299 & 1.5 & -0.006 & 0.875 & -0.008 & 0.113 & 0.194 & $<0.0001$ & 25.2 & 80 \\
\hline \multirow{2}{*}{ IDFdk3-A } & 2002 & 10 & 2 & 182 & 2.0 & -0.409 & $<0.0001$ & 0.003 & 0.834 & 0.411 & $<0.0001$ & 15.7 & 30 \\
\hline & 2006 & 14 & 3 & 181 & 1.25 & 0.194 & $<0.0001$ & -0.030 & $<0.0001$ & 0.132 & 0.009 & 36.7 & 45 \\
\hline \multirow{2}{*}{ IDFdk3-B } & 1992 & 8 & 3 & 50 & 2.0 & 0.368 & $<0.0001$ & -0.022 & $<0.0001$ & - & - & 44.3 & 92 \\
\hline & 1999 & 15 & 5 & 59 & 1.25 & 0.186 & 0.0007 & -0.026 & 0.015 & - & - & 13.4 & 78 \\
\hline \multirow{2}{*}{ IDFdk3-C } & 1992 & 12 & 3 & 49 & 1.25 & 0.395 & $<0.0001$ & -0.031 & $<0.0001$ & - & - & 64.4 & 86 \\
\hline & 1999 & 19 & 5 & 51 & 1.25 & 0.223 & 0.007 & -0.083 & 0.0003 & - & - & 49.8 & 67 \\
\hline \multirow{2}{*}{ SBSdw1-A } & 1992 & 10 & 2 & 49 & 1.5 & 0.172 & 0.0009 & -0.044 & $<0.0001$ & - & - & 51.0 & 73 \\
\hline & 1999 & 17 & 5 & 59 & 1.25 & 0.322 & 0.629 & -0.458 & 0.015 & - & - & 69.8 & 73 \\
\hline \multirow{2}{*}{ SBSdw1-B } & 1992 & 11 & 2 & 47 & 1.0 & 0.194 & 0.002 & -0.027 & 0.002 & - & - & 35.0 & 79 \\
\hline & 1999 & 18 & 5 & 55 & 1.5 & 0.318 & $<0.0001$ & -0.136 & $<0.0001$ & - & - & 40.8 & 65 \\
\hline
\end{tabular}

${ }^{1}$ Years of pine diameter growth subsequent to the determination of CHR.

${ }^{2}$ Number of lodgepole pine-centred subplots contributing to the analysis.

Individual principal competitor aspen variables included basal area $\left(\mathrm{cm}^{2} / \mathrm{stem}\right)$, height $(\mathrm{cm})$, aspen-pine height difference $(\mathrm{cm})$, and aspen-pine HR. Area-based variables included density (stems $/ 10 \mathrm{~m}^{2}$ subplot) and basal area $\left(\mathrm{cm}^{2} / 10 \mathrm{~m}^{2}\right.$ subplot). Trends in these statistics were qualitatively examined to provide insight into possible mechanisms behind observed differences in the competitive strength of aspen in different ecological units and on different sites.

\subsubsection{Evaluating the Influence of Principal Competitor Aspen} Density on Pine Vigour. Logistic regression analysis, based on a mixed model with a fixed treatment effect and random block and treatment $\times$ block effects, was used to evaluate the risk at age 17-20 of lodgepole pine vigour declining to unacceptable levels (i.e., dead/moribund or in poor condition) with increasing density of aspen having $\mathrm{HR} \geq 1.5$ at age $8-12$. The value 1.5 was chosen based on the finding that CHR tended to be in the range 1.25-1.5 when stands were older than 10 years (see Section 3). Vigour was selected for this analysis because its qualitative nature allows the integration of a number of aspects of health that are difficult to quantify. For purposes of comparison with earlier work that focused on aspen as tall as or taller than target pine [9], the same analysis was repeated using density of aspen having $\mathrm{HR} \geq 1.0$. All lodgepole pine included in the analysis had moderate or good vigour in the first assessment, when they were 8-12 years old (Table 2). For each model, the odds of pine vigour being unacceptable (i.e., the probability of being unacceptable divided by the probability of being acceptable) was calculated, and an odds ratio (the multiplicative factor by which risk changed when the independent variable increased by one unit) was estimated. Odds ratios above 1 indicate increased risk and those below 1 indicate decreased risk. Summary statistics describing the prevalence (by type and cause) of damage to foliage, leaders, and stems of lodgepole pine having unacceptable vigour at age 17-20 years were compiled.

All data analyses were carried out using SAS statistical software [19]. Simple regression analyses (Models 1 and 2) were performed with PROC MIXED, and logistic regression analyses were performed with PROC GLIMMIX.

\section{Results}

3.1. Critical Height Ratio (CHR). At the youngest sampled stand ages (8-12 years), CHR ranged from a maximum of 3.25 in the 11-year-old SBPSxc stand to a minimum of 1.0 in the 11-year-old SBSdw1-B stand (Table 2, Figure 1). At the SBSdw1-B site, CHR increased to 1.5 by the time the stand was 18 years old, but values at all other sites either decreases with age or remained constant. CHR values at all sites were consistently 1.25 to 1.5 when stands were $14-19$ years old.

When stands were 8-12 years old, maximum $R^{2}$ values associated with models predicting lodgepole pine growth from aspen density according to stepwise downward addition of HR classes (used to define CHR) ranged from low (15.7\%) to moderately high $(64.4 \%)$ at the three IDF sites and were intermediate at the SBPSxc and SBS sites (25.3 to 51.0\%) (Table 2, Figure 2). The proportion of subplots having $\geq 1$ PC (principal competitor) aspen was highest (92\%) at the 8 -year-old IDFdk3-B site and lowest (30\%) at the10-yearold IDFdk3-A site (Table 2). The maximum $R^{2}$ value that defined CHR at the IDFdk3-A site increased to moderate $(36.7 \%)$ when the stand was 14 years old, and the proportion of subplots having $\geq 1 \mathrm{PC}$ aspen increased to $45 \%$. At the IDFdk3-B and IDFdk3-C sites, the maximum $R^{2}$ defining CHR decreased as the stands aged. At the IDFdk3-B site, the decrease in maximum $R^{2}$ was substantial, from $44.3 \%$ at age 

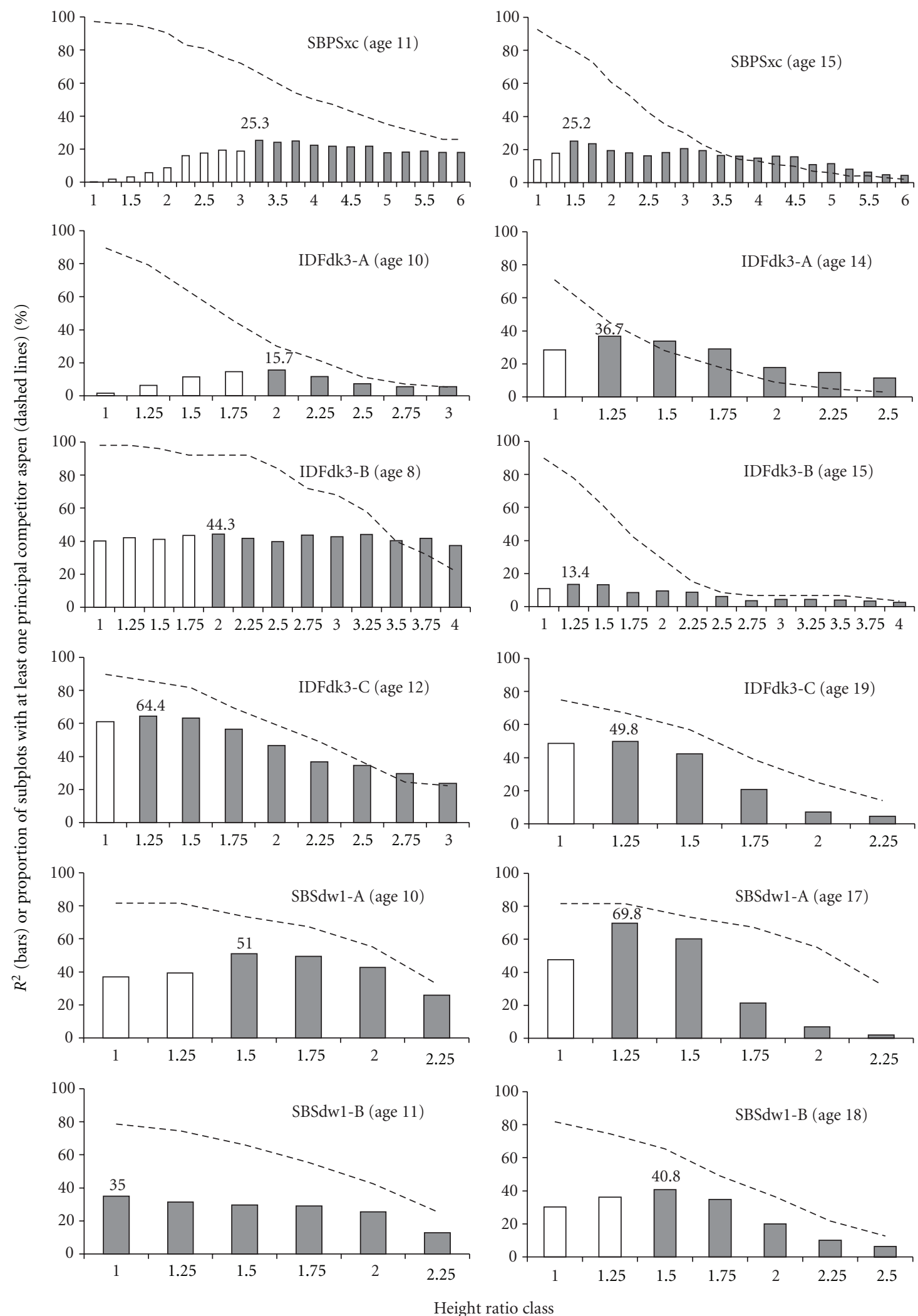

FIGURE 1: $R^{2}$ for predicting 2-5-year pine diameter growth (bars) and the proportion of subplots having at least one aspen stem (lines) for each aspen/pine HR class, at two stand ages at each of the six study sites. CHR is the lowest HR class designated by a gray bar. Analysis was conducted in a downward manner, so the analysis for a given class includes aspen in that class and all HR classes above it. 


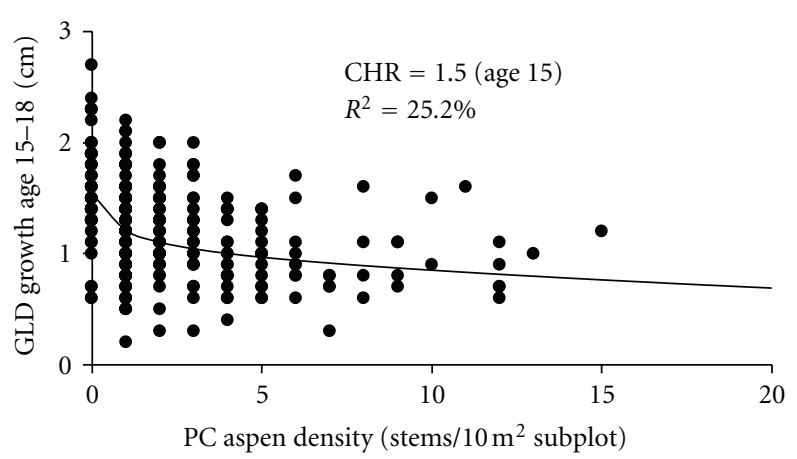

(a)

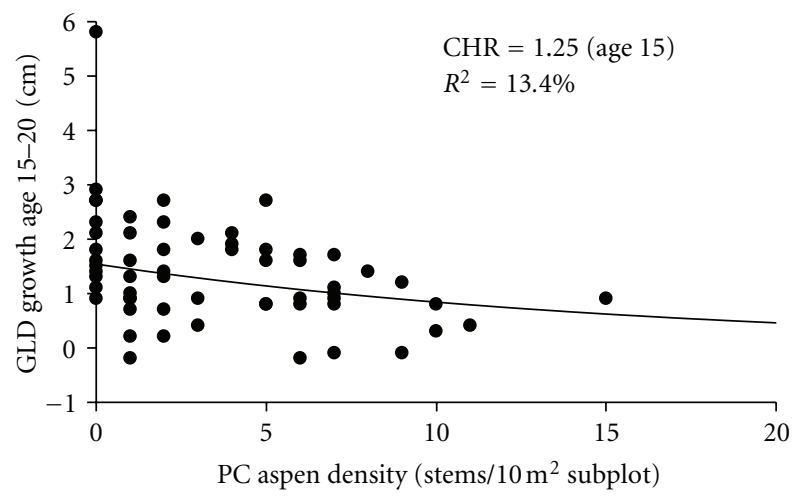

(c)

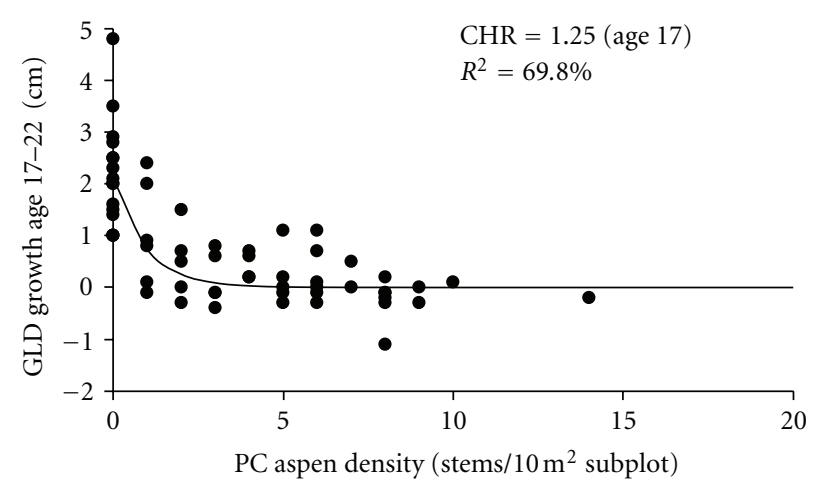

(e)

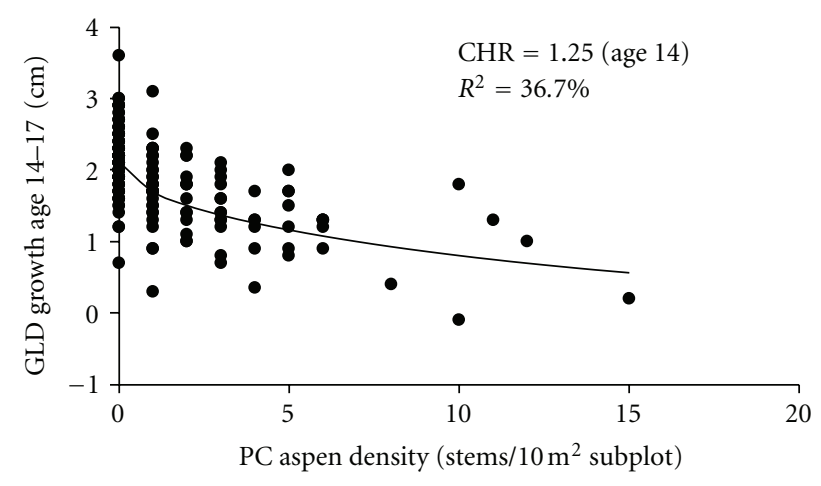

(b)

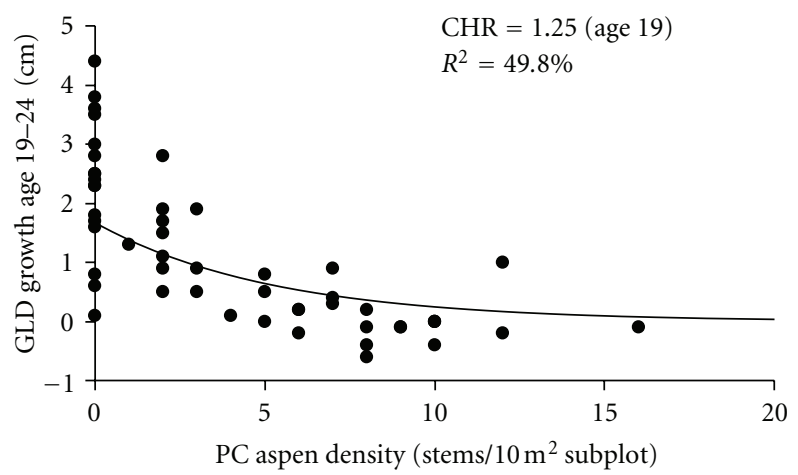

(d)

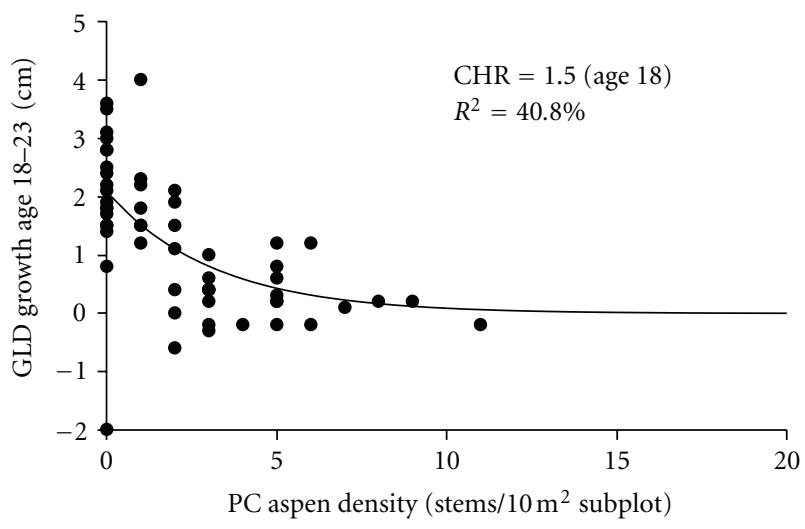

(f)

FIgURE 2: Scatterplots and fitted regression curves predicting lodgepole pine diameter growth from principal competitor aspen density determined at age 14-19 years at the six study sites: (a) SBPSxc; (b) IDFdk3-A; (c) IDFdk3-B; (d) IDFdk3-C; (e) SBSdw1-A; (f) SBSdw1-B.

8 to $13.4 \%$ at age 15 . At both these sites, the proportion of subplots having $\geq 1 \mathrm{PC}$ aspen decreased in comparison with the first CHR determination but continued to be above $65 \%$. At the SBPSxc site, the maximum $R^{2}$ value defining CHR was stable between stand ages of 11 and 15 , but the proportion of subplots having $\geq 1$ PC aspen increased from 66 to $80 \%$. The maximum $R^{2}$ value defining CHR increased at both the SBS sites as stands aged from 10-11 years old to 17-18 years old. The increase in $R^{2}$ was steeper at the SBSdw1-A site ( 51.0 to $69.8 \%$ ) than at the SBSdw1-B site (35.0 to $40.8 \%$ ). The proportion of subplots having $\geq 1$ PC aspen remained constant over time at the SBSdw1-A site and decreased at the SBSdw1-B site (Table 2).

Except for the SBSdw1-B site where CHR was 1.0 at age 11, correlation coefficients for models predicting lodgepole pine diameter from the density of PC aspen were higher than they were when models used $\mathrm{HR}=1.0$ (i.e., when all aspen at least as tall as the target pine were included). When basal area of PC aspen was used to predict target lodgepole pine diameter growth, $R^{2}$ values for SBPS and IDF site models were consistently lower than when density of principal competitor aspen was used, regardless of stand age (Figure 3). At 


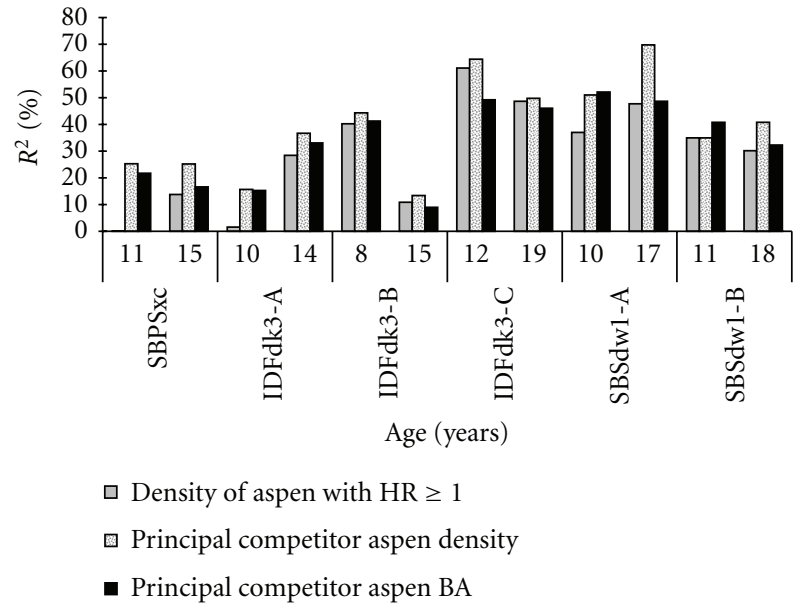

Figure 3: Comparison of $R^{2}$ values for models predicting 2-5-year pine diameter growth from (a) the density of aspen with aspen/pine height ratio $\geq 1.0$, (b) principal competitor aspen density, or (c) principal competitor basal area.

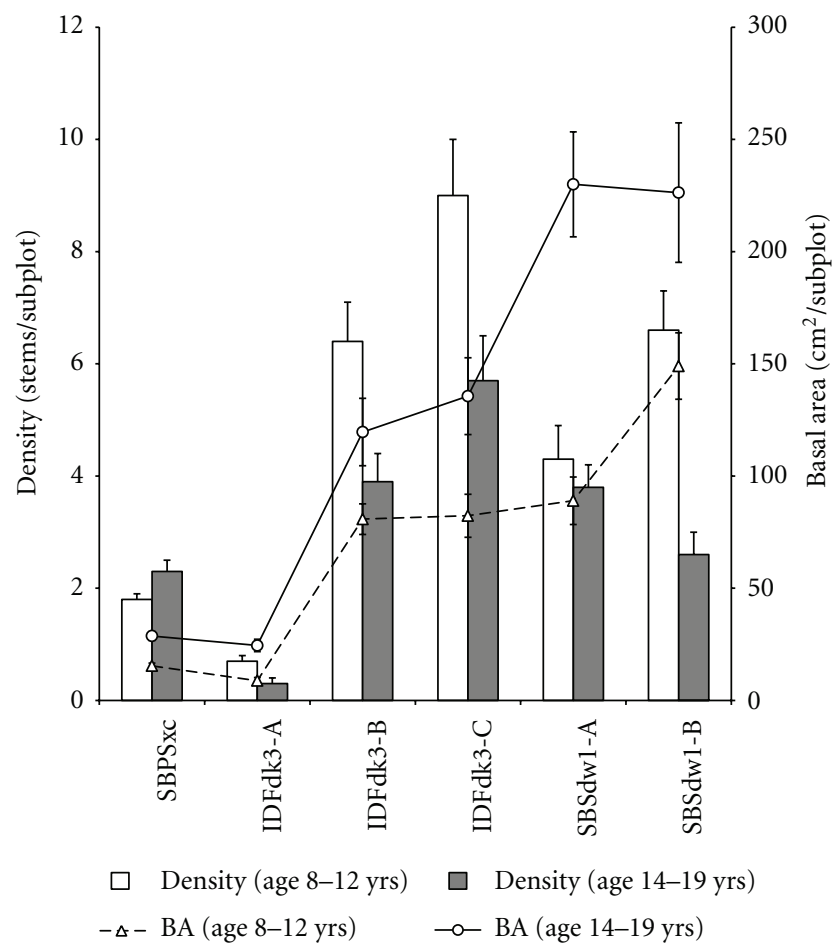

FIgURE 4: Average principal competitor density and basal area per $10 \mathrm{~m}^{2}$ subplot at individual sites at age 8-12 and age 14-19. Error bars are one standard error.

the SBS sites, $R^{2}$ values for models that used basal area to predict pine diameter were slightly higher than for those that used density of PC aspen at age 10-11, but density explained more variation than basal area when $\mathrm{CHR}$ was determined at age 17-18 (Figure 3).

3.2. Characteristics of Principal Competitor (PC) Aspen. Individual PC aspen on all sites increased in height and basal area per stem (Table 3), as did average height and total basal

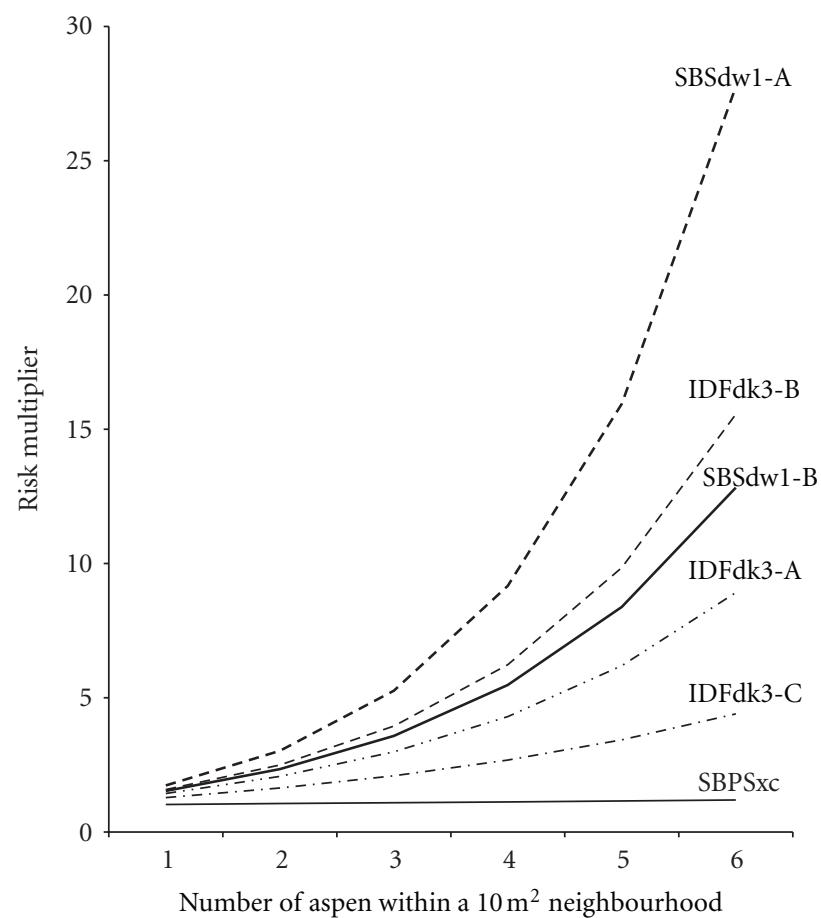

FIGURE 5: Increase in risk of unacceptable pine vigour at age 17-20 with increasing density of aspen stems having $\mathrm{HR} \geq 1.5$ (assessed within a $10 \mathrm{~m}^{2}$ subplot) at age 6-12.

area per subplot (Figure 4). At age 15-18, PC aspen on the SBS sites were 3-4 times as tall as those on the SBPS site, and individual stems had 5-7 times the basal area. Principal competitor aspen on IDF sites were intermediate in size. The mean height difference between PC aspen and target lodgepole pine decreased as the SBPSxc and IDFdk3-A stands aged, but it increased with stand age at all other sites (Table 3). The average height ratio between PC aspen and target pine decreased with increasing stand age at the SBPSxc, IDFdk3-A, and IDFdk3-B sites (Table 3). In comparison, height ratio was relatively stable as stands aged at the IDFdk3-C, SBSdw1-A, and SBSdw1-B sites, with increases or decreases $\leq 0.4 \%$ (Table 3 ).

3.3. Relationships between Principal Competitor Aspen Density and Lodgepole Pine Vigour. At all sites, the risk of target lodgepole pine vigour declining to unacceptable levels increased with increasing aspen density at both $\mathrm{HR} \geq 1.5$ and $\mathrm{HR} \geq 1.0$ (Table 4, Figure 5). For HR $\geq 1.5$, estimated odds ratios for individual sites ranged from 1.03 to 1.74 , decreasing in the order of SBSdw1-A > IDFdk3-B > SBSdw1B $>$ IDFdk3-A $>$ IDFdk3-C $>$ SBPSxc. For HR $\geq 1.0$, estimated odds ratios for individual sites ranged from 1.0 to 1.56 and decreased in the order of SBSdw1-B $>$ IDFdk3-B > SBSdw1-A > IDFdk3-C > IDFdk3-A > SBPSxc (Table 4).

\section{Discussion}

Principal aspen competitors in the 14-19-year-old stands we examined were consistently $\geq 1.25-1.5$ times taller than 


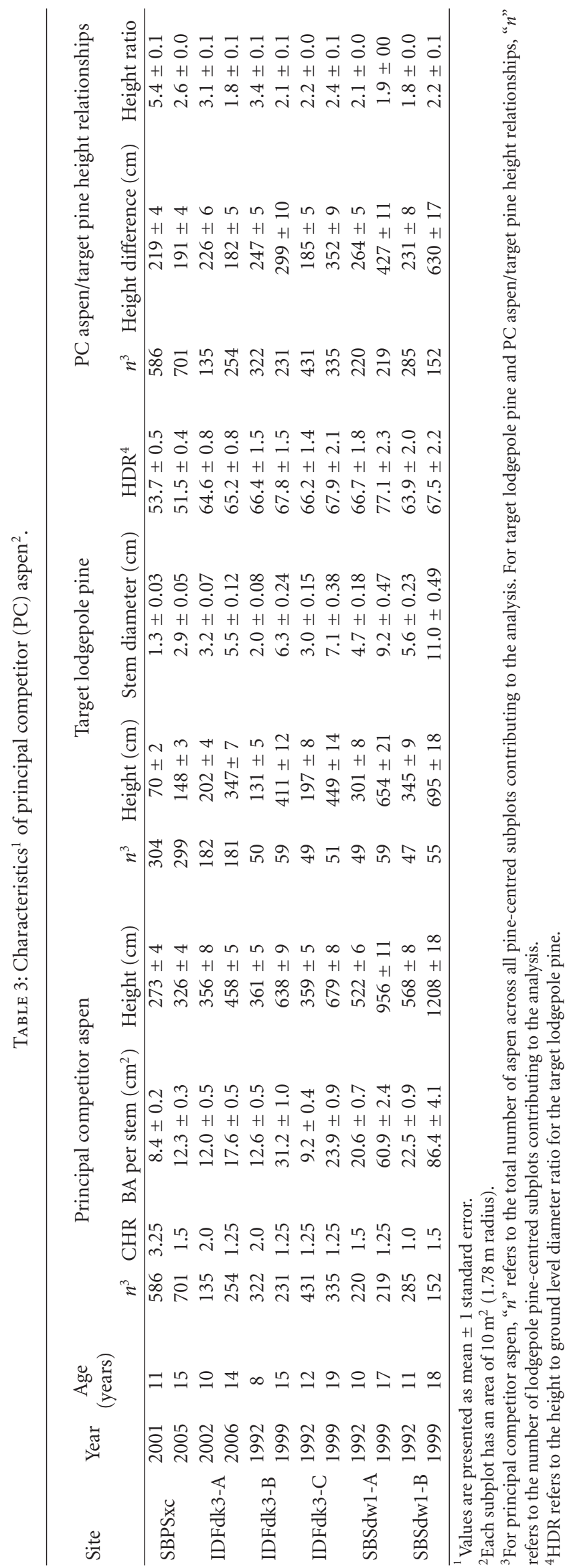


TABLE 4: Odds ratios and confidence limits associated with risk of lodgepole pine having unacceptable vigour as the density of neighbouring aspen with $\mathrm{HR} \geq 1.5$ and $\mathrm{HR} \geq 1.0$ increases by one stem.

\begin{tabular}{lccccccccc}
\hline \multirow{2}{*}{ Site } & \multicolumn{3}{c}{$n^{1}$} & \multicolumn{2}{c}{ Pine age (years) } & \multicolumn{3}{c}{ HR $\geq 1.5$} & \multicolumn{3}{c}{ HR $\geq 1.0$} \\
& & HR assessed & Vigour assessed & Odds ratio & LCL $^{2}$ & UCL $^{2}$ & Odds ratio $^{\text {LCL }^{2}}$ & UCL $^{2}$ \\
\hline SBPSxc & 304 & 11 & 18 & 1.03 & 0.94 & 1.11 & 1.00 & 0.93 & 1.07 \\
IDFdk3-A & 183 & 10 & 17 & 1.44 & 1.20 & 1.72 & 1.19 & 1.08 & 1.31 \\
IDFdk3-B & 50 & 8 & 20 & 1.58 & 1.20 & 2.08 & 1.53 & 1.18 & 1.97 \\
IDFdk3-C & 49 & 12 & 17 & 1.28 & 1.10 & 1.49 & 1.30 & 1.12 & 1.50 \\
SBSdw1-A & 51 & 10 & 17 & 1.74 & 1.27 & 2.38 & 1.50 & 1.20 & 1.87 \\
SBSdw1-B & 51 & 11 & 18 & 1.53 & 1.16 & 2.02 & 1.56 & 1.18 & 2.07 \\
\hline
\end{tabular}

${ }^{1}$ " $n$ " refers to the number of lodgepole pine-centred subplots contributing to the analysis.

${ }^{2}$ LCL is lower $95 \%$ confidence limit; UCL is upper 95\% confidence limit.

target lodgepole pine, regardless of ecological unit. Despite similarity of the critical height ratio across the six sites, principal competitor aspen in different ecological units, and even on sites within the same ecological unit, varied considerably in size, importance to lodgepole pine diameter growth, and the risk they posed to pine vigour. The risk of lodgepole pine vigour declining to unacceptable levels with increasing presence of principal competitor aspen also differed between sites in different ecological units, as did the importance of competition from principal competitor aspen to lodgepole pine as stands aged. Previous examination of competitive relationships between lodgepole pine and trembling aspen that were of equal or greater height demonstrated that competitive interactions differed by ecological unit and also illustrated that aspen-pine height relationships changed variably over time in the different subzones and variants $[9,10]$. Our current analysis showed that correlation coefficients did not increase with the inclusion of aspen below a height ratio of 1.25 at stand ages of 14-19-years, which is consistent with the understanding that light availability within aspen canopies increases dramatically above a relative height of 0.7 [12]. In our study, density of principal competitor aspen was a more successful predictor of lodgepole pine diameter growth than was aspen basal area (Figure 3), contrasting with the work of Comeau et al. [12] which showed basal area to be the measure of aspen abundance that was most highly correlated with under- and within-canopy light levels.

The importance of principal competitor aspen to lodgepole pine diameter growth (as represented by $R^{2}$ values) generally decreased in the order of SBSdw1 $>$ IDFdk $3>$ SBPSxc. We had expected this result based on previous studies in this geographic region $[9,10,12]$ and because competitive effects increase with site productivity [20]. We acknowledge that the relatively small subplot radius of $1.78 \mathrm{~m}$ (used to allow comparison across ecosystems) may have caused us to underestimate the importance of competition on SBSdw1 sites where there was a large aspen-pine height differential. Lieffers et al. [21] suggested that a much larger plot size was necessary to adequately assess light interception by trembling aspen. However, that study involved slower growing white spruce in a boreal ecosystem, where trembling aspen has greater ability to intercept light [12]. Our previous work suggested that in colder, drier ecosystems, where the height differential between aspen and pine is small, the inclusion of aspen up to $2.6 \mathrm{~m}$ away from the target pine did not improve models [10].

In the SBPSxc, which was the least productive ecological unit we examined [17], the importance of aspen competition remained consistently low (adjusted $R^{2}$ of $25 \%$ ) as the stand aged from 11 to 15 years, despite a slight increase in the number of subplots having at least one PC aspen, which was probably attributable to aspen growth responses to the reduction in intraspecific competition that was created by the thinning treatments. Decreasing aspen-pine height difference and height ratio (Table 3 ) and decreasing average density of principal competitor aspen within target pine neighbourhoods (result not presented) together suggest that lodgepole pine is outgrowing trembling aspen and that the importance of aspen competition, at least for light, is likely to decrease as the stand ages. At age 15, individual principal competitor aspen at the SBPSxc site averaged less than $3.5 \mathrm{~m}$ tall and had average basal area of $12.3 \mathrm{~cm}^{2}$, which, when compared with individual aspen size in the IDFdk3 and SBSdw1, helps explain why the risk of lodgepole pine vigour declining to unacceptable levels was extremely low at the SBPSxc site, regardless of the number of neighbouring principal competitor aspen stems (Table 4, Figure 5).

Based on studies concerning environmental constraints on trembling aspen development, it is likely that slow growth in the SBPSxc is due primarily to the cold, dry climate [2224]. Trembling aspen is more sensitive to cold soil conditions than lodgepole pine [25]. Aspen's ability for water uptake is limited at soil temperatures below $10^{\circ} \mathrm{C}$, which can inhibit shoot growth for up to a month after air temperatures become favorable for growth [23]. Weakly developed clayenriched restricting layers are also relatively common in the SBPSxc [26], so that summer drought may pose further growing season limitations to aspen growth. The annual frost-free period was also short at our SBPSxc study site (Table 1), which was associated with reduced aspen height growth in another southern British Columbia study [27].

In 14-19 year-old IDFdk3 stands, principal competitor aspens were $\geq 1.25$ times as tall as target pine at all three sites and the average size of individual principal competitor aspen stems (height and basal area) was consistently intermediate between that of the SBPSxc and SBSdw1 sites. However, the importance of competition to lodgepole pine and the average height of aspen relative to pine varied strongly between 
sites. Adjusted $R^{2}$ values at age $14-19$ ranged from $13.4 \%$ to $49.8 \%$, having decreased since age $8-12$ years at two sites and increased at the third (Table 2). Average density and basal area per subplot were also highly variable at the three IDFdk3 sites (Figure 4). Differences in the competitive importance of principal competitor aspen and in their characteristics among the three IDFdk3 sites illustrate the need to investigate factors other than aspen presence that may be affecting lodgepole pine performance in this biogeoclimatic variant. Newsome et al. [9] suggested that lodgepole pine could tolerate five taller aspen stems within a $1.78 \mathrm{~m}$ radius (i.e., 5000 stems/ha); however, the low odds ratios produced by logistic regression analysis in this study suggest the threshold may be even higher. In the current study, we found that the risk of lodgepole pine vigour declining to unacceptable levels with increasing principal competitor aspen density was low in the IDFdk3. The IDFdk3-B site was an exception because the presence of western gall rust (Endocronartium harknessii (J.P. Moore) Y. Hirat) increased the likelihood that lodgepole pine would have unacceptable vigour. At the other sites, declines in lodgepole pine vigour were primarily the result of aspen competition (data not shown) and were accompanied by decreases in stem diameter.

The variable competitive effects of trembling aspen presence on lodgepole pine in the IDFdk3 variant may be related to differences in climatic and edaphic conditions, as well as to the influence of factors such as aspen density in the original stand, clonal biomass, or pathogen presence on the density and vigour of principal competitor aspen [28-30]. The IDFdk3 is the most extensive variant of the IDF zone in south-central British Columbia, occurring on rolling plateaux to the west and east of the Fraser River basin. As a result, there is a relatively wide range of average annual precipitation between lower elevation areas bordering dry valley-bottom ecosystems and eastern regions that are adjacent to wetter biogeoclimatic units [26]. Soils of the IDF zone are characterized by a well-developed clay-enriched restricting layer that occurs at a depth of $20-35 \mathrm{~cm}$ [26]. Other studies have associated such a feature with reduced aspen height growth [31]. Shallow rooting depth almost certainly contributes to summer soil moisture deficits, which are common in warm, dry units such as the IDFdk3 [32]. Messier et al. [33] have suggested that aspen leaf area index is lower on dry than moist sites, which presumably affects its competitive ability. Summer drought has also been observed to cause extensive top dieback among mature trembling aspen [34]. Chen et al. [24] indicate that trembling aspen site index increases with increasing latitude in the IDF zone and at its western reaches, which suggests that it may be more competitive in the IDFdk3 than in more southerly or easterly variants.

The SBSdw1 was the most productive ecosystem we examined [17], and trembling aspen was consistently a strong competitor with lodgepole pine at our two study sites. The importance of principal competitor aspen density to lodgepole pine diameter growth was variable between the two SBSdw1 study sites but there was a consistent trend of increasing importance of competition over time (Table 2). Logistic regression analysis also showed that the risk of declining vigour increased steeply with increasing density of principal competitor aspen (Tables 2 and 4, Figure 5). This is consistent with earlier findings by Newsome et al. [9] that competition from aspen as tall or taller than the target pine became increasingly important in the SBSdw1 up to an age of at least 24 years and that lodgepole pine size and vigour declined where more than one neighbouring taller aspen stem was present within a $1.78 \mathrm{~m}$ radius (i.e., where aspen densities exceeded 1000 stems/ha). In the present study, principal competitor aspen in 17-18-year-old SBSdw1 stands were, on average, 3 to 4 times taller than those in the SBPSxc and had 5 to 7 times greater basal area (Table 3 ). Aspen stem diameter has been positively correlated with crown characteristics associated with light interception [12, 14], and Comeau et al. [12] also found that aspen in the SBS zone intercepted more light per unit basal area than aspen in the IDF or SBPS zones. Although climate is somewhat similar in the SBS and IDF zones of south-central British Columbia, SBS zone soils are typically developed over base-rich morainal deposits and are loamy and well-drained [26] — features which other studies have associated with high trembling aspen site index $[22,24]$. On both the SBSdwlsites, we found that, although height ratios were relatively constant over time, the average absolute difference in height between principal competitor aspen and target pine increased substantially up to a stand age of $17-18$ years.

\section{Conclusions and Management Implications}

Previous examination of juvenile trembling aspen-lodgepole pine mixtures on zonal sites in south-central British Columbia focused on the competitive effects of aspen as tall or taller than target pine. This was partly in response to an earlier exploratory study that suggested that aspen were competitive where $H R \geq 1.0$ [16] and also to test provincial standards for aspen retention. At the time this set of experiments was initiated, regulations regarding the retention of broadleaf trees in conifer plantations were very conservative. Aspen taller than 67 to $80 \%$ of the conifer height were considered to be potentially competitive. Standards were subsequently relaxed to allow a minor presence of aspen of equal or greater height [2] but were still predicated on the assumption that aspen had strong competitive ability across a wide spectrum of ecosystems and that the negative impacts on conifers would increase with age. In contrast, subjective observations and subsequent experimental findings indicated that the competitive ability of aspen varied widely across ecological units even within a relatively small geographic range $[9,10]$.

Although we recognize that this study does not have adequate replication at the subzone/variant level to make formal statistical inferences, it does provide greater experimental rigour than has been available to date. Our current and previous findings together suggest that administrative guidelines pertaining to aspen-pine relative height and aspen density in the SBSdw1, IDFdk3, and SBPSxc biogeoclimatic units are overly conservative. The present study showed that aspen less than 1.25 times as tall as lodgepole pine did not contribute substantially to competition on any of the zonal sites we examined, regardless of ecosystem. Newsome et al. [9] 
previously suggested thresholds of one and five aspen of equal or greater height within a $1.78 \mathrm{~m}$ radius of target pine in the SBSdw1 and IDFdk3 variants, respectively, and these thresholds of 1000 and 5000 stems/ha should now be tested using a height ratio of 1.25. Our current results further indicate that trembling aspen has very little competitive importance to lodgepole pine in the SBPSxc and that declines in vigour with increasing density were negligible. Along with the lack of lodgepole pine response to reduced aspen abundance reported by Newsome et al. [10], this result suggests that brushing aspen to ensure good lodgepole pine performance is most likely biologically unnecessary in the SBPSxc. Eliminating superfluous brushing treatments would not only encourage ecological diversity and resilience over time [7] but would substantially reduce stand tending costs.

\section{Acknowledgments}

This research has been funded over the years by the BC Ministry of Forests and Range Forest Resource Development Agreement, Forest Renewal BC, and most recently by the Forest Investment Account. Funding assistance by the agencies does not imply endorsement of any statements or information presented here. Valuable advice and support during the initiation of this project was provided by Nola Daintith, Lyn Konowalyk, Guy Newsome, Craig Sutherland, Phil Comeau, Lorne Bedford, Paul Rehsler, and Ken Soneff. Scott and Janet Zimonick, Craig Smith, and David Sword provided field support. The authors thank Phil Comeau, Richard Kabzems, Gordon Nigh, and Allan Powelson for review comments during preparation of this paper.

\section{References}

[1] K. Klinka, J. Worrall, L. Skoda, and P. Varga, The Distribution and Synopsis of Ecological and Silvical Characteristics of Tree Species of British Columbia's Forests, Canadian Cartographics, Coquitlam, Canada, 2000.

[2] British Columbia Ministry of Forests, Establishment to Free Growing Guidebook. Cariboo Forest Region, Forest Practices Code of British Columbia Guidebook, Forest Practices Branch, B.C. Ministry of Forests, Victoria, Canada, 2002.

[3] J. Pastor, "Nutrient cycling in aspen ecosystems," in Aspen Symposium Proceedings, 1989. General Technical Report NC140, p. 18, United States Department of Agriculture, Forest Service, St. Paul, Minn, USA, 1990.

[4] S. W. Simard, S. W. Hagerman, D. L. Sachs, J. L. Heineman, and W. J. Mather, "Conifer growth, root disease, and plant community responses to mechanical and chemical control of birch and aspen in southern British Columbia's temperate mixed forests," Canadian Journal of Forest Research, vol. 35, no. 4, pp. 843-859, 2005.

[5] R. Kabzems and O. García, "Structure and dynamics of trembling aspen-white spruce mixed stands near Fort Nelson, B.C," Canadian Journal of Forest Research, vol. 34, no. 2, pp. 384-395, 2004.

[6] P. G. Comeau, R. Kabzems, J. McClarnon, and J. L. Heineman, "Implications of selected approaches for regenerating and managing western boreal mixedwoods," Forestry Chronicle, vol. 81, no. 4, pp. 559-574, 2005.
[7] S. Simard and A. Vyse, "Trade-offs between competition and facilitation: a case study of vegetation management in the interior cedar-hemlock forests of southern British Columbia," Canadian Journal of Forest Research, vol. 36, no. 10, pp. 24862496, 2006.

[8] J. L. Heineman, S. W. Simard, D. L. Sachs, and W. J. Mather, "Trembling aspen removal effects on lodgepole pine in southern interior British Columbia: ten-year results," Western Journal of Applied Forestry, vol. 24, no. 1, pp. 17-23, 2009.

[9] T. A. Newsome, J. L. Heineman, and A. F. L. Nemec, "Competitive interactions between juvenile trembling aspen and lodgepole pine: a comparison of two interior British Columbia ecosystems," Forest Ecology and Management, vol. 255, no. 7, pp. 2950-2962, 2008.

[10] T. A. Newsome, J. L. Heineman, and A. F. L. Nemec, "A comparison of lodgepole pine responses to varying levels of trembling aspen removal in two dry south-central British Columbia ecosystems," Forest Ecology and Management, vol. 259, no. 6, pp. 1170-1180, 2010.

[11] D. Meidinger and J. Pojar, Ecosystems of British Columbia, B.C. Ministry of Forests, Victoria, Canada, 1991.

[12] P. Comeau, J. Heineman, and T. Newsome, "Evaluation of relationships between understory light and aspen basal area in the British Columbia central interior," Forest Ecology and Management, vol. 226, no. 1-3, pp. 80-87, 2006.

[13] C. N. Filipescu and P. G. Comeau, "Aspen competition affects light and white spruce growth across several boreal sites in western Canada," Canadian Journal of Forest Research, vol. 37, no. 9, pp. 1701-1713, 2007.

[14] B. D. Pinno, V. J. Lieffers, and K. J. Stadt, "Measuring and modelling the crown and light transmission characteristics of juvenile aspen," Canadian Journal of Forest Research, vol. 31, no. 11, pp. 1930-1939, 2001.

[15] T. Wang, A. Hamann, D. L. Spittlehouse, and S. N. Aitken, "Development of scale-free climate data for western Canada for use in resource management," International Journal of Climatology, vol. 26, no. 3, pp. 383-397, 2006.

[16] T. Newsome, J. L. Heineman, and A. F. L. Nemec, "Competitive effects of trembling aspen on lodgepole pine performance in the SBS and IDF zones of the Cariboo-Chilcotin Region of South-central British Columbia," Technical Report 005, Research Branch, B.C. Ministry of Forests, Victoria, Canada, 2003.

[17] British Columbia Ministry of Forests and Range, Site Index Estimates by Site Series: Report by Biogeoclimatic Unit (2008 Approximation), Forest Science Program, Victoria, Canada, 2011.

[18] S. Navratil and D. A. MacIsaac, "Competition index for juvenile mixed stands of lodgepole pine and aspen in west-central Alberta," Tech. Rep. 57, Forestry Canada, Alberta, Canada, 1993.

[19] SAS Institute, SAS 9.2, Cary, NC, USA, 2002-2008.

[20] J. P. Grime, Plant Strategies, Vegetation Processes, and Ecosystem Properties, John Wiley \& Sons, Chichester, UK, 2nd edition, 2001.

[21] V. J. Lieffers, B. D. Pinno, and K. J. Stadt, "Light dynamics and free-to-grow standards in aspen-dominated mixedwood forests," Forestry Chronicle, vol. 78, no. 1, pp. 137-145, 2002.

[22] D. A. Perala, "Quaking aspen (Populus tremuloides Michx.)," in Silvics of North America: II. Deciduous, R. M. Burns and B. H. Honkala, Eds., Technical Coordinators, pp. 555-569, United States Department of Agriculture Handbook, 1990.

[23] X. Wan, S. M. Landhäusser, J. J. Zwiazek, and V. J. Lieffers, "Root water flow and growth of aspen (Populus tremuloides) 
at low root temperatures," Tree Physiology, vol. 19, no. 13, pp. 879-884, 1999.

[24] H. Y. H. Chen, P. V. Krestov, and K. Klinka, “Trembling aspen site index in relation to environmental measures of site quality at two spatial scales," Canadian Journal of Forest Research, vol. 32, no. 1, pp. 112-119, 2002.

[25] D. S. Green, "Describing condition-specific determinants of competition in boreal and sub-boreal mixedwood stands," Forestry Chronicle, vol. 80, no. 6, pp. 736-742, 2004.

[26] O. A. Steen and R. A. Coupé, A Field Guide to Forest Site Identification and Interpretation for the Cariboo Forest Region, Land Management Handbook, B.C. Ministry of Forests, Victoria, Canada, 1997.

[27] J. L. Heineman, D. L. Sachs, S. W. Simard, and W. Jean Mather, "Climate and site characteristics affect juvenile trembling aspen development in conifer plantations across southern British Columbia," Forest Ecology and Management, vol. 260, no. 11, pp. 1975-1984, 2010.

[28] R. R. Martin, J. G. Berbee, and J. O. Omuemu, "Isolation of a potyvirus from declining clones of populus," Phytopathology, vol. 72, no. 9, pp. 1158-1162, 1982.

[29] B. R. Frey, V. J. Lieffers, A. D. Munson, and P. V. Blenis, “The influence of partial harvesting and forest floor disturbance on nutrient availability and understory vegetation in boreal mixedwoods," Canadian Journal of Forest Research, vol. 33, no. 7, pp. 1180-1188, 2003.

[30] S. D. Wullschleger, T. M. Yin, S. P. DiFazio et al., "Phenotypic variation in growth and biomass distribution for two advanced-generation pedigrees of hybrid poplar," Canadian Journal of Forest Research, vol. 35, no. 8, pp. 1779-1789, 2005.

[31] D. A. Perala, "Manager's handbook for aspen in the NorthCentral States," Tech. Rep. NC-36, United States Department of Agriculture, Forest Service, 1977.

[32] D. Lloyd, K. Angove, G. Hope, and C. Thompson, A Guide to Site Identification and Interpretation for the Kamloops Forest Region, Land Management Handbook, B.C. Ministry of Forests, Victoria, Canada, 1990.

[33] C. Messier, S. Parent, and Y. Bergeron, "Effects of overstory and understory vegetation on the understory light environment in mixed boreal forests," Journal of Vegetation Science, vol. 9, no. 4, pp. 511-520, 1998.

[34] E. H. Hogg, J. P. Brandt, and M. Michaelian, "Impacts of a regional drought on the productivity, dieback, and biomass of western Canadian aspen forests," Canadian Journal of Forest Research, vol. 38, no. 6, pp. 1373-1384, 2008. 

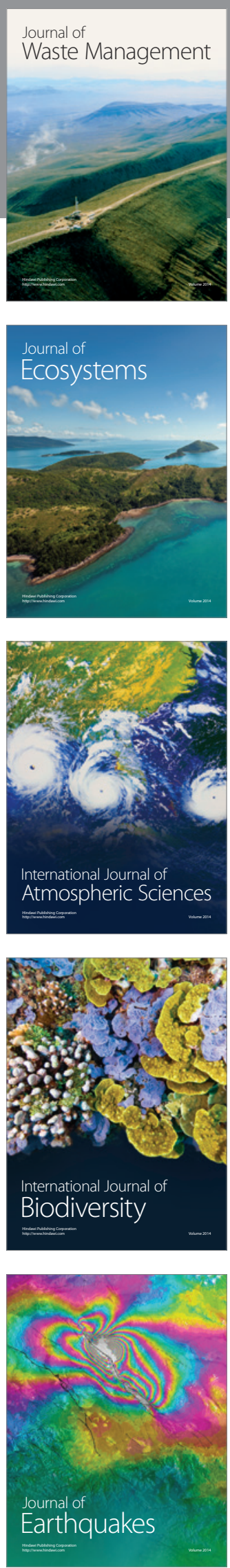
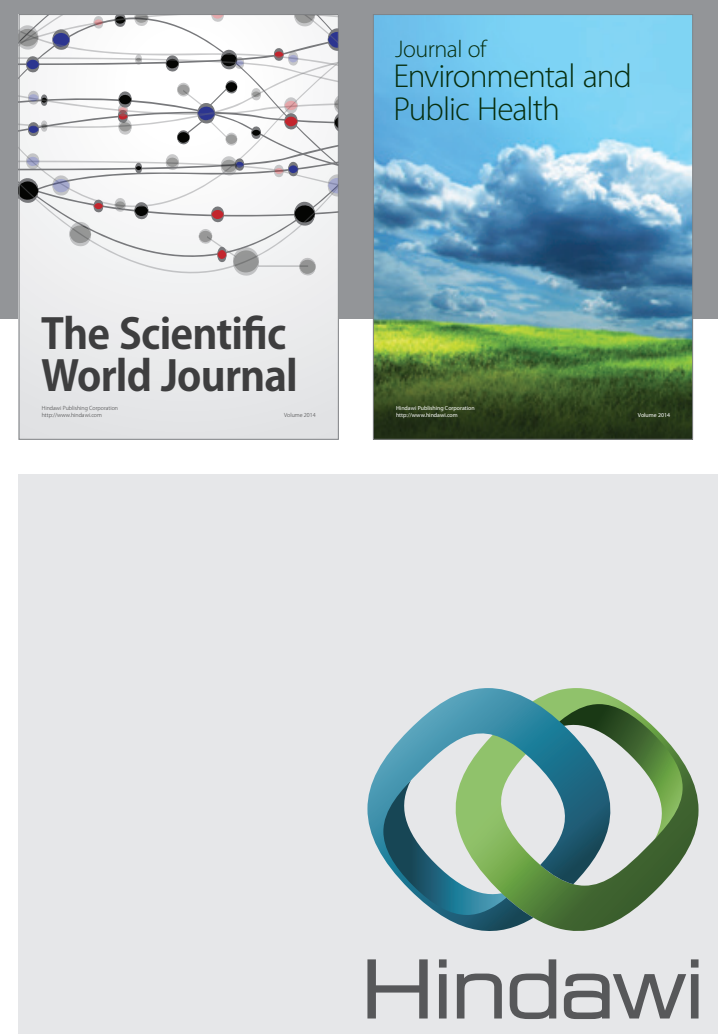

Submit your manuscripts at

http://www.hindawi.com
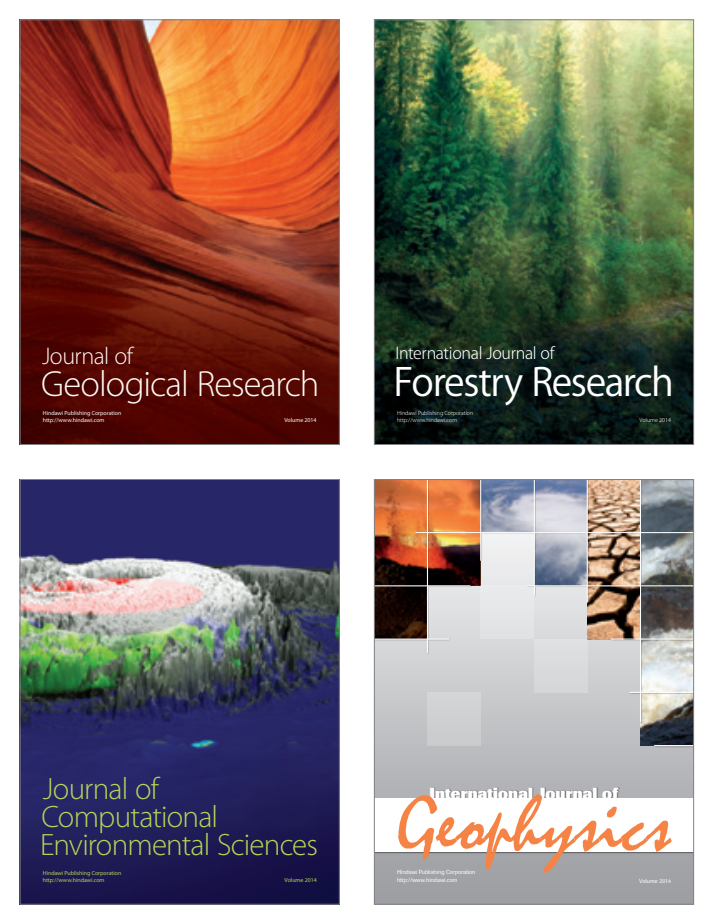
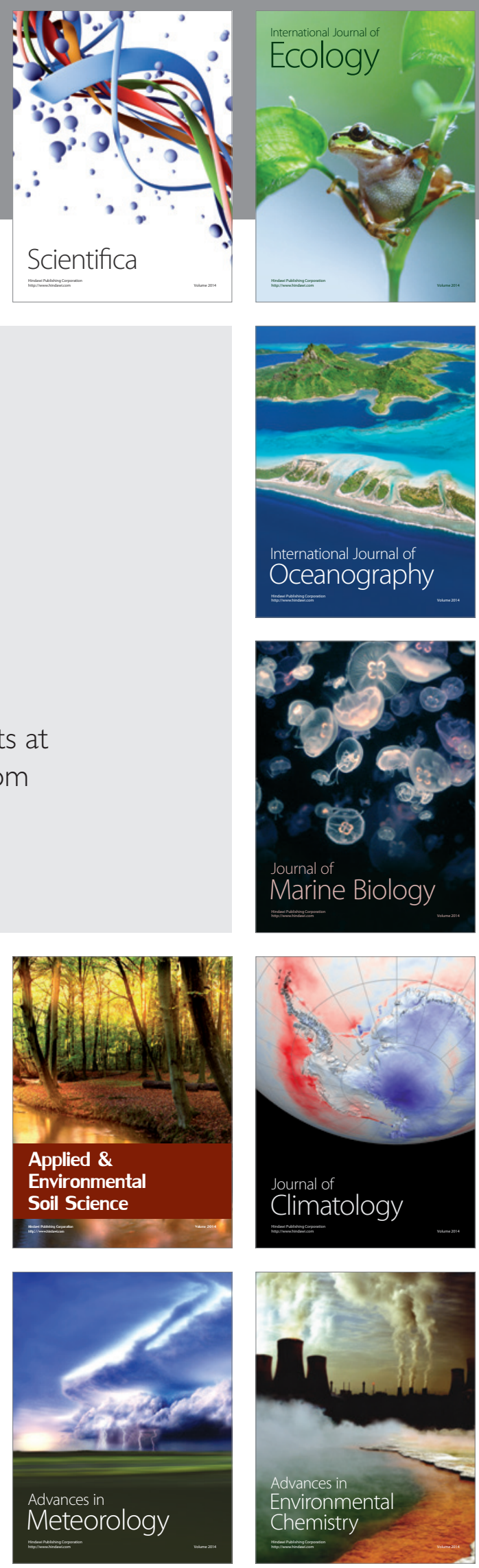